REVISTA DE ESTUDOS EM ARTES CÊNICAS

E-ISSN 2358.6958

\title{
Insistir na presença - Tentativas de invenção teatral e pedagógica em isolamento
}

\author{
Lucienne Guedes Fahrer
}

\section{Para citar este artigo:}

FAHRER, Lucienne Guedes. Insistir na presença Tentativas de invenção teatral e pedagógica em isolamento. Urdimento - Revista de Estudos em Artes Cênicas, Florianópolis, v. 3, n. 42, dez. 2021.

do) DOI: http:/dx.doi.org/10.5965/1414573103422021e0116

Este artigo passou pelo Plagiarism Detection Software| iThenticate 


\title{
Insistir na presença - \\ Tentativas de invenção teatral e pedagógica em isolamento
}

\author{
Lucienne Guedes Fahrer ${ }^{1}$
}

\begin{abstract}
Resumo
A experiência da prática teatral teve que se deslocar para outros lugares e modos de operação, por conta do distanciamento social necessário ao contexto pandêmico. $\mathrm{O}$ artigo discorre sobre tentativas pedagógicas e artísticas realizadas no trabalho com turmas de graduação em universidade pública, apoiando-se em referências de áreas diversas e a partir da insistência em criar eventos ao vivo como objeto de estudo e relação com o público. Ao invés do enfoque analítico, o artigo escolheu aproximar-se de palavras e temas que vieram à sala de trabalho pela força das circunstâncias remotas, como forma de desenvolver uma primeira reflexão a respeito dos enfrentamentos e incertezas da criação teatral.
\end{abstract}

Palavras-chave: Teatro. Processo de criação. Pedagogia teatral. Arte no contexto pandêmico.

\section{To insist on presence - Attempts at theatrical and pedagogical invention in social distance}

\begin{abstract}
The theatrical practice experience had to adapt to atypical sites and different plans of action, due to the necessary social distancing in the pandemic context. The article explores pedagogical and artistic attempts realized through students in graduate classes at a public university, based on different perspectives, and developed from the creative initiative in live events as an object of study and connection to the audience. Preferably to the analytical approach, the choice is to consider words and themes that came into view during the work in class resulting from the remote circumstances, as a way to introduce an initial consideration on the challenges and uncertainties of the theatrical creation.
\end{abstract}

Keywords: Theatre. Creative process. Pedagogy of theatre. Art in the pandemic context. 
Insistir el la presencia -

Intentos de invención teatral y pedagógica en tiempos de aislamiento

\section{Resumen}

La experiencia de la práctica teatral, tuvo que trasladarse a otros lugares y modos de operación debido a la distancia social necesaria en el contexto de la pandemia. El artículo discute los intentos pedagógicos y artísticos realizados en clases de graduados en una universidad pública, a partir de referencias bibliográficas de diferentes áreas de conocimiento y desde la insistencia en la creación de eventos en vivo como objeto de estudio y relación con los espectadores. En lugar de un enfoque analítico y reflexivo, el artículo opta por abordar palabras y temas que llegaron a la sala de trabajo virtual, como forma de desarrollar una primera reflexión sobre los enfrentamientos e incertidumbres de la creación teatral.

Palabras clave: Teatro. Proceso creativo. Pedagogía del teatro. Arte en el contexto de la pandemia. 


\section{Palavras iniciais}

No dia 11 de março de 2020 a Universidade Estadual de Campinas - UNICAMP mandou uma comunicação suspendendo as atividades presenciais por quinze dias. Naquele momento, ninguém foi capaz de imaginar que o aviso não era exagerado e nem que os quinze dias virariam muito mais de um ano. Atônitos, professores e alunos mantivemos os trabalhos em suspensão, a princípio como se pudéssemos em breve voltar à normalidade dos processos de criação em sala de aula. Assim, ao invés de começar uma montagem para um espetáculo, ficamos suspensos, mas não à deriva, em estudos e leituras, às margens do mergulho na criação, esperando o momento de voltar à sala.

Essa suspensão durou algumas semanas. As leituras e os encontros online eram espaçados, frouxos, condescendentes com as dificuldades de adaptação de todos. Muitos estudantes voltaram para suas cidades, tentavam encontrar maneiras para ter conexão de qualidade... mas a resistência em aceitar o que acontecia era maior do que qualquer resiliência.

No momento em que percebemos, todos, que a suspensão era realmente necessária e que duraria por ainda muito tempo, a bifurcação da escolha se materializou à nossa frente, de maneira imperativa e nada poética: seguimos ou paramos? Será possível fazer teatro sem presença? Será possível transformar a frustração de jovens, que apostaram muito na formação universitária, em material humano de criação potente? Qual seria o preço da recusa? Qual o peso da nossa escolha, como integrantes de uma universidade pública? Seguir ou parar?

A escolha não foi simples. E ainda não é possível conhecer seus efeitos, nem mesmo vislumbrar futuros ou fazer planos que sejam minimamente plausíveis. Foi preciso aceitar a incerteza como condição, reconhecer a efemeridade como parte da vida, assim como a inconstância, o perigo, o risco e a importância do afeto com todas as suas letras.

Ao longo de quinze meses que nos separavam daquele março, diferentes hipóteses foram sendo colocadas em ação, algumas tentativas de cena e de presença. Lançamos mão dos textos de algumas autoras e autores para mover as 
questões adiante, alargando o campo de estudos para o cinema, para as artes visuais, para a educação, a literatura, a psicologia e a filosofia. De qualquer forma, por ser muito recente, não é ainda possível falar com convicção sobre o que estamos vivendo e fazendo. Portanto, este texto é trabalho de cartografia; são mapas e desenhos que se fazem enquanto se navega. Segundo Suely Rolnik, para um cartógrafo, para uma atitude-cartógrafo, "teoria é sempre cartografia - e, sendo assim ela se faz juntamente com as paisagens cuja formação ele acompanha” (Rolnik, 2014, p.65 - grifo da autora). É também por isso que, neste texto, a questão da motivação, que move ou deixa de mover a criação e o aprendizado, aparecerá muitas vezes em primeiro plano. "O princípio do cartógrafo é extramoral [...] O que the interessa nas situações com as quais lida é o quanto a vida está encontrando canais de efetuação" (Rolnik, 2014, p.68 - grifo da autora).

A reflexão cartográfica aqui disposta encontrou sua forma numa espécie de ensaio alfabético, uma organização provisória de palavras, temas e conceitos com os quais nos deparamos desde o começo da pandemia, mas que ainda andam soltos por aí. Essas palavras vibram em nossos corpos atravessados pelo isolamento. Nós: estudantes e professora, talvez também as muitas pessoas do público que nos encontrou. ${ }^{2}$

\section{Alfabeto de influências, percepções \\ e tentativas de invenção teatral em isolamento}

A, de autorregulação: um processo complexo e cíclico, através do qual o estudante de artes cênicas pode se tornar, ou não, agente de sua própria aprendizagem, sobre si mesmo ou sobre a linguagem. Nela estão envolvidos pensamentos, emoções e comportamentos. Nas tentativas de ação no ensino remoto, essa palavra foi uma das mais presentes nesse vocabulário diferente que começamos a falar. É um processo complexo porque foi preciso desenvolver a motivação prévia e o interesse de cada estudante, para além das dificuldades

${ }^{2}$ As experiências a partir das quais este texto foi escrito, orientadas e dirigidas pela autora do artigo, foram: (1) os processos de criação e apresentação de 9 trabalhos cênicos, realizados ao vivo, através de telefone e internet, cada um deles por ao menos 40 vezes, no 1‥ semestre de 2020; (2) o processo de criação de um trabalho realizado ao vivo com um grupo de 12 alunos no 2‥ semestre de 2020; e (3) as dinâmicas de improvisação em disciplina de graduação, no 1‥ semestre de 2021. 
naturais de um processo de criação. Foi preciso interferir nas estratégias de aprendizagem já comuns, foi preciso criar condições para que todos fôssemos percebendo, a cada passo, como a produção de conhecimento estava acontecendo. Compartilhar abertamente das estratégias de motivação e mostrar explicitamente o valor que cada conteúdo proposto possuía, para além das descobertas individuais, foi se mostrando bastante eficaz. Foi preciso estarmos atentos ao nível de complexidade que cada dinâmica pedia, já que uma tarefa muito fácil na sala de aula presencial - como prestar atenção à própria respiração, por exemplo - pode se tornar bastante difícil na sala da própria casa. O esforço para promover o pertencimento, ou ainda a noção de agrupamento, foi também um desafio à parte.

Tudo mudou de lugar. O que realmente se tornou essencial para ser vivido e aprendido, nas novas circunstâncias? Diante da vontade de desistir, o que se pode fazer a si mesmo e aos outros? A capacidade de autorregulação influencia nas ações a serem tomadas, porque está diretamente relacionada à motivação, questão pedagógica central:

Alunos desmotivados estudam muito pouco ou nada e, consequentemente, aprendem muito pouco. Em última instância, aí se configura uma situação educacional que impede a formação de indivíduos mais competentes para exercerem a cidadania e realizaremse como pessoas, além de se capacitarem a aprender pela vida afora (Boruchovitch e Bzuneck, 2009, p.13).

Com a distância, a percepção dos estudantes sobre si mesmos e sobre o grupo, assim como a disposição e a coragem para explicitar o que veem, serão aliadas importantíssimas para que a professora tenha condições de mudar de direção, se necessário, de agregar dissonâncias, de conseguir fazer com que a voz do trabalho soe suficientemente audível nas casas - lugares estes que nós, professores, não conseguimos ver nem ouvir plenamente. Precisa existir a confiança de que estamos todos na mesma página, para que ninguém nos escape sem querer, pertinência colocada na afetividade, também.

Mas, afinal, como dar chance à autorregulação? Algumas tentativas: (1) Dar importância central a reflexões livres sobre os acontecimentos de cada aula, em 
dinâmicas de jogo que incluam expressões em primeira pessoa. No nosso caso, com o exercício de uma escrita pessoalizada, foi-se criando um terreno seguro em que as coisas podiam ser ditas, mesmo as problemáticas. (2) Deixar que ocorram necessárias mudanças de rumo, mesmo que sejam drásticas, sem que isso signifique fraqueza da relação professor-aluno. (3) Através do compartilhamento de experiências próprias em narrativas, permitir a todos que possam dizer de sua relação com os textos teóricos estudados: "como os textos passaram por mim?" (4) Elaborar outras questões coletivamente. (5) Não fazer "chamada", mas dar a chance de fazer com que, através das dinâmicas de jogo e criação, as ausências não sejam desapercebidas nem suavizadas em seus efeitos. (6) Saber o nome de todos, dos lugares onde estão, incluir essas materialidades nas dinâmicas da aula. (7) Empenhar um tempo da aula perguntando realmente como as coisas estão; trocar a expressão "gastar tempo" por “empenhar tempo". (8) Desenvolver capacidade de ver com "olhos de abelhas", espécie de visão periférica em todas as direções, para que se possa enxergar todos os quadrados da tela do computador onde os outros estão. (9) Dar atenção aos gestos, deixar claro que estão sendo percebidos; dar-se conta dos momentos em que os alunos mais escondidos chegam ao plano do protagonismo; avaliar quais disparadores estimularam isso. (10) Dar valor real às tarefas pedidas, alinhavando desdobramentos e, ao mesmo tempo, permitindo que os atrasados possam se agregar.

B, de banda larga. Nem sempre tão larga assim. Às vezes, os estudantes estão com a câmera desligada por conta da internet ruim, segundo eles próprios. Às vezes eles saem da aula e não voltam mais porque ficaram sem internet. Faltando três minutos para começar a apresentação final, ao vivo, online, uma aluna avisa por mensagem: "não sei se vou conseguir, está chovendo muito aqui e a internet cai".

O terreno é movediço. As discussões éticas e políticas ganham muita importância nas aulas. Cada mínima atitude constitui o território do aprendizado. Nesse tempos de alta dependência de internet, é preciso considerar outras coisas para além da pontualidade e da presença. 
Então, como uma aula pode ser uma boa aula, com uma conexão desigual e claudicante? Dois, dos quatro requisitos que para Marilena Chauí ${ }^{3}$ (2019) são considerados aqueles que precisam configurar o bom aprendizado, ficam balançados. Ao menos dois dos quatro pés da cadeira estão trincados. Segundo a professora e filósofa, o primeiro requisito é a aula estar bem preparada. O segundo é a percepção, por parte dos alunos, de que a aula estabelece um pensamento em movimento contínuo, porque é um percurso que faz parte de um todo ainda maior. O terceiro requisito seria os alunos se lembrarem do que foi tratado anteriormente, o que pode ser percebido pelas perguntas e pelas anotações que fazem. O quarto é que a aula permita um bom final do curso, que cada dia seja importante e crie condições para que o trabalho final seja bom. Supondo que seja possível preparar bem a aula, que os professores consigam isto sem ainda dominar o que de melhor pode ser feito à distância: como fazemos para conseguir manter o movimento contínuo de pensamento, apesar da internet falhar? Como fazem os alunos para se lembrarem daquilo que foi dito, justamente quando a tela travou?

C, de câmera. O grande e único olho por onde tudo passa, nas aulas. A câmera pode ser uma aliada. Ou uma oponente. A gente pode permitir que ela seja motivo de liberação da nossa fala e expressão, dos nossos desejos, da nossa busca pela conexão efetiva com os outros. Ou então ela pode ser dispositivo de controle, motivo de embotamento, de sensação patética de solidão talvez acompanhada.

Supondo que, como nos apresenta Giorgio Agamben, não exista possibilidade de os dispositivos (computador, celular, câmeras) atuarem para a liberdade e para a liberação, e que somos, os seres humanos, "incessantemente capturados" e que não haveria "um sonho distante na vida dos indivíduos que não seja modelado, contaminado ou controlado por algum dispositivo": o que nos resta, então, é assumir que "a estratégia que devemos adotar no nosso corpo a corpo com os dispositivos não pode ser simples, já que se trata de nada menos que liberar o que foi capturado e separado pelos dispositivos para restituir um possível uso comum" 
(Agamben, 2005, p.13-14).

Do que pode ser feita tal estratégia, então? Se escolhemos insistir, qual corpo a corpo ativar com esses dispositivos? Algumas tentativas: (1) Brincar com a câmera. (2) Transformar suas cores e texturas. (3) Recusar as ideias prontas, ou seja, fugir da captura do enquadramento tipo selfie, do close de viés melodramático, do plano médio comum. (4) Recusar o que "não pode". (5) Relativizar a nitidez, o contraste, a estabilidade e a solidão que as câmeras nos impõem.

A gente experimentou dançar com o outro lá do outro lado; a gente experimentou criar outros planos temporais; a gente experimentou fazer do espectador uma outra qualidade da ideia de personagem, desestabilizando os tipos de interlocução; a gente fez a cena virar redemoinho com o celular preso num arame que girava pela área de serviço; a gente experimentou a câmera como um parquinho para o outro; a gente experimentou jogar a câmera no balde de água, na piscina; a gente trouxe a câmera para dentro da casinha de bonecas. A ideia: recusar o adestramento que esse olho-câmera impõe aos corpos da gente.

E se pudermos de fato unir a câmera à sua expressão? E se ela não for só o "olho do monstro", mas justamente o fundamento, a cor, a textura, o canal, a circunstância? Como é possível não tomar o dispositivo como alienação e retomar para si o desejo de "transformar o que há de imediato na vivência cotidiana em não imediato”? (Oiticica, 1986, p.50).

D, de dramaturgia. Ou dessa dramaturgia que sofre a condição de distância em que nos encontramos. Ela é atingida, atravessada, precisa falar de outros jeitos. Os processos de criação vividos nessa sala de aula à distância nos devolveu à pergunta fundamental: o que quero que minha arte faça, para qual tipo de encontro quero convidar o público? Será que é para um encontro em que as pessoas espectadoras se sentem na solidão de suas casas e, através de uma tela, vejam atrizes a fazer algumas coisas, interpretar papéis e personagens talvez interessantes? Será só isso? Como será possível, mediados todos por computadores e celulares, insistir na presença, insistir no aqui-agora, insistir na 
presença de um quase agora e com certeza num não aqu?

Tentativa: em um dos processos desenvolvidos em 2020, sete trabalhos individuais foram apresentados. Cada atriz ou ator preparou as cenas para um, dois ou três espectadores, no máximo. Os trabalhos duravam por volta de meia hora; os dez primeiros minutos eram empenhados só no primeiro contato, garantindo a presença efetiva dos dois lados.

Tudo começava uma semana antes, com um formulário preenchido por quem queria ver o trabalho. A partir do formulário, as atrizes e os atores - agora também produtores - entravam em contato e agendavam o encontro. No dia certo, frio na barriga, rezando para a internet não cair, a apresentação começava com uma ligação de telefone, seguida por uma chamada de vídeo, com câmeras ligadas. E ali, já em contato visual, tinha início a demorada cena inicial, que tinha como tarefa instaurar um espaço preponderantemente ficcional, sem abandonar o espectador à própria sorte. Era preciso, e esta era a aposta, levar o espectador pela mão até a ficção poder acontecer sem ausências. Não era questão somente de adaptar dramaturgias já existentes; era preciso perguntar o que se queria com o público, naquelas condições, e também permitir aos estudantes fazer a cena e ao mesmo tempo estudar como conseguir.

E, de engajamento. Proporcionar a ligação do estudante com a sua criação, com o seu trabalho sobre si mesmo. Garantir um espaço (virtual) para que a produção de conhecimento flua não pode ser de exclusividade do professor. Por exemplo: para além de pedir reiteradas vezes, como conseguir que as câmeras dos estudantes estejam ligadas, que tenham vontade de falar e expor seus gestos e pensamentos? Como fazer com que o pertencimento não se desmanche? São dois, os lados: professores e estudantes com o desejo de agir, modificando suas maneiras de pensar, alimentando o desejo pelo encontro e pela criação. É preciso fazer alguma coisa.

Do outro lado, os corpos sonolentos, a pouca luz revelando esconderijos propositais. Do outro lado, famílias em variadas situações de exposição ao vírus da pandemia, diferentes condições de acesso à internet. Do outro lado, muitas 
pessoas jovens que não precisavam trabalhar, agora precisam. Antes, na sala presencial, aquecimentos e jogos coletivos. Agora, que cada um se vire sozinho, como puder. Se o "corpo cênico experimenta espaço e tempo potencializados e, também, o corpo cênico potencializa tempo e espaço", como nos sussurra o texto de Eleonora Fabião (Fabião, 2010, p. 321), como mover isso tudo, tempo e espaço, sozinhos e em casa?

Algumas tentativas: (1) Ler textos, juntos, que nos lembrassem do corpo cênico potencializando tempo e espaço. (2) Garantir a prática de jogos em que o pensamento de todos pudesse ter espaço na sala de aula todos os dias. (3) Elevar a importância de tudo que é dito e feito na aula à categoria de ação. (4) Chamar a todos pelos nomes, sempre. (5) Dar um jeito de alimentar minha própria motivação e inquirir meu engajamento como docente e artista todos os dias.

Há muita coisa em jogo: o aprendizado, a universidade pública, os afetos, a criação, e, em última e primeira instâncias, a vida de todos nós, ali. A aula de teatro ultrapassou o teatro, teve que ultrapassar.

F, de falta. Não tem sala, não tem corredor, não tem gente ali, não tem espectadores, não tem mão no ombro, não tem abraço. Tem o quê, então? Tratouse de olhar para o copo todos os dias, a escolher se estava meio cheio ou meio vazio. A tentativa de vê-lo como estando meio cheio começou assim: em meados de maio de 2020, quando já sabíamos que estaríamos nas aulas de maneira remota por bastante tempo, escolhi e trouxe um texto teatral, para a montagem. Já que o plano de trabalho pressupunha estudo de personagens dramáticos, achei que seria bom fazê-lo através de um texto brasileiro, criando um campo politizado para as questões que apareciam nas conversas informais sobre o nosso momento histórico. Mas não, nada disso; não ia dar certo. Faltava tudo, de ânimo a argumento. Como professora e diretora, virei a mesa do jogo rapidamente, e acredito que o gesto abrupto tenha salvado a todos nós, ali. Se não era a peça trazida por mim a que ia agregar as forças, que cada um trouxesse seus interesses, então; que fosse a escolha do material dramatúrgico o motivo de engajamento. E aconteceu um ponto de virada: a energia da sala, do empenho, começou a aumentar geometricamente. De repente, um dia, o copo apareceu meio cheio. 
Não acredito que a mudança tenha sido positiva somente pelo fato dos estudantes terem escolhido seus materiais. Foi, principalmente, por terem visto, por si mesmos, quantas coisas esta escolha implica. "Não é simples nem fácil ter autonomia”, escutei algumas vezes: aqui estava a escolha. Era pegar ou largar. A autonomia deixou de ser palavra para ter que ser atitude.

Então, perguntamos: que falta na autonomia?

G, de gambiarra. Atitude gambiarra. Fazer arranjos de coisas supracicladas, fora de seu uso comum, de objetos quebrados e cheios de falhas, pedaços de coisas juntadas. Fazer uso de técnicas, de soluções e de ideias improváveis a serviço da cena. Cooptar materialidades existentes nos espaços e nas características arquitetônicas das casas como dramaturgia inevitável.

Nada do que se tinha era ideal para se fazer o que se precisava. Fazer as cenas a partir das próprias casas revelava não só ambientes "emprestados" para as cenas, mas também todo um modo de vida privado que se fazia agora público e exposto. Foi preciso fazer esquemas de todo tipo: pendurar celulares, prender o cachorro na área de serviço, "trancafiar" as outras pessoas da família na cozinha durante a cena, encontrar plásticos coloridos que pudessem fazer as vezes de gelatina colocadas à frente de luminárias de quarto, negociar com todos da casa o uso do espaço, negociar o silêncio, avisar os vizinhos que durante uma hora poderia haver gritaria. A câmera voltada para o céu mostrava a atriz de baixo para cima e só algumas copas de árvores, fazendo o quintal pequeno se transformar numa cidade rural da Espanha de Lorca. A sala toda branca, retirados e empilhados os móveis num canto, quis constituir um plano em outra dimensão, espiritual. A câmera do celular operada por uma companheira de moradia tremia de propósito e gerava um quase terremoto na cena. As plantas da entrada da casa viravam dramaturgia explícita. O cômodo ainda em construção virou cela de penitenciária feminina. A garrafa de água posta no exato ângulo entre a atriz e a câmera do celular oferecia metáfora para o momento distorcido da trajetória da personagem. Mais do que criatividade, essas gambiarras envolveram a constatação de três coisas que se tornaram fundamentais: o apoio dos vizinhos e companheiros de moradia, a negociação do uso do espaço e o exercício da supraciclagem para 
sustentar os pontos de vista do olho da câmera.

A atitude gambiarra foi fundamental e resultou na abordagem estética do trabalho. Uma estética precária que pôs a cena entre o documentário e a ficção, colocando o efeito câmera como teatralidade difusa. E também provisória, porque, como as cenas criadas insistiam no evento ao vivo, evidenciavam muito daquilo que escapava da ideia fechada de personagem. Havia ali, exposta e inevitável, a pessoa que performa, seu modo de vida, sua casa, os depoimentos silenciosos dos objetos e das pessoas que moram com ela e que às vezes e por acidente se deixavam ver como fantasmagorias, numa passagem no fundo da cena, num canto ou num grito fora de hora. Ainda que à revelia, a cena revelava a contingência da verdade (Coutinho, 2013, p.22), para usar o termo do cineasta Eduardo Coutinho. Embora não fosse empenho garantir um distanciamento atriz-personagem, inevitavelmente o processo de criação teve que se submeter à discussão, pela força estética dos elementos precários e de uso cotidiano ali dispostos. A materialidade dos ambientes da vida privada pôde funcionar como um distanciamento ao revés, não necessariamente harmonizado com o discurso das cenas, mas no entanto possível de ser tolerado amigavelmente e também estrangeiramente

H, de hoje. A internet falha, cai. Às vezes volta, às vezes não. As pessoas têm tido mais problemas na vida do que o usual. Ansiedade, tristeza, apatia: palavras que aparecem cada vez mais nas conversas em sala de aula. Se as condições de vida e de estudo estão atravessadas por descontinuidades e rupturas, uma tentativa de ação pedagógica efetiva se dá diretamente na preparação dos encontros: fazer com que cada aula se configure como um todo, que cada encontro de criação seja único, como um programa de ação. Tais programas, nas nossas aulas, eram elaborados para serem feitos com uma tarefa especial e própria, para que cada aula pudesse se completar em si mesma e, ao mesmo tempo, estar ligada a outros programas, como se fossem uma série. Poderíamos

${ }^{4}$ O termo é usado por Sarrazac, a respeito do desvio da obra teatral. Para ele, no edifício teatral "a arte do desvio não deixa de se relacionar com o distanciamento brechtiano: afastar-se da realidade, considerá-la instalando-se à distância e de um ponto de vista estrangeiro a fim de melhor reconhecê-la [...]. O desvio permite um retorno perturbador - estrangeirificante - a essa realidade que queríamos testemunhar". Sarrazac, 2012, p.65. 
dizer que a aula sempre é um programa de ação. Mas, agora, esta elaboração e forma de ação ganharam o primeiro plano do pensamento pedagógico e também artístico. Empresto aqui o que diz Eleonora Fabião a respeito do programa de ação:

O programa é o enunciado da performance: um conjunto de ações previamente estipuladas, claramente articuladas e conceitualmente polidas a ser realizado pelo artista, pelo público ou por ambos sem espaço prévio. [...] É este programa/enunciado que possibilita, norteia e move a experimentação (Fabião, 2013, p.13 - grifo da autora).

Hoje. O outro dia, depois. Cada dia uma coisa, a aula como programa também performático. Se a conexão cair, haverá o próximo dia. O que será posto em experiência e experimentação hoje? O que vai mover a gente no encontro único? Cada dia uma ação em si, naquele dia, agora. Depois a gente vê o amanhã.

I, de incerteza. Construir uma casa na incerteza, é a imagem. Deixar a invenção e a problematização estarem no lugar da aula, da criação. Do lado da professora, do lado dos estudantes. Agora, nesses tempos, nos lembramos todo dia o quanto a vida é incerta (na verdade, quando é que não foi?). Assim, trata-se de deixar a incerteza entrar como condição do trabalho de criação, como condição da vida, como condição do artista. O artigo de Virginia Kastrup entrou de vez na sala de aula:

Acolher e habitar incertezas é uma questão de aprendizagem. A questão aqui é a da aprendizagem inventiva, que inclui a capacidade de problematizar, de criar novos problemas. Trata-se de instaurar uma política cognitiva da invenção (Kastrup, 2016, p.4).

Não se trata de ter que seguir ensaiando, preparando, dando e assistindo às aulas à distância, a qualquer custo, como se nada estivesse acontecendo, ou como se pouca coisa estivesse nos pondo em perigo. Trata-se de realizar tentativas de inventar novas questões, tanto pedagógicas como artísticas, e também afetivas, que possam ao menos não nos paralisar diante do mundo que nos paralisou, e ainda por cima deixar que certa dose de alegria se instaure como política.

J, de jogo. O jogo como estratégia para garantir o estar no tempo presente. A base da cena, de tudo o que fazemos, ainda é o jogo. Só que, agora, os enunciados 
ganham maior importância, porque quem orienta não consegue interferir muito no meio da realização, não pode alterar com precisão o rumo do que está sendo feito. Isso pelo simples fato de que não será possível ouvir direito, via internet, durante o jogo; todas as vozes saem do mesmo lugar, todas chegam no mesmo autofalante. No enunciado, resta explicar bem o caminho, a dinâmica, e esperar que tudo corra bem. E só. A autonomia se torna ainda mais importante: por mais que se possa envolver a todos para a hora do jogo, resta no fundo a consciência de que estamos todos sozinhos.

\begin{abstract}
A qualquer momento um ator se depara com um dilema em particular: escolher entre desfazer-se da experiência ou concentrá-la. É fácil se desfazer. É só deixar ir, deixar fluir sempre que se sentir cheio. Mas acredito que é importante para um ator aprender a necessidade de concentrar as irritações, os sentimentos aleatórios, as dificuldades, as paixões, tudo que acontece de momento a momento, para depois comprimi-los, deixa-los acontecer e encontrar os momentos adequados para a expressão clara e articulada. O resultado será uma expressão e não um desfazimento aleatório (Bogart, 2009, p.36).
\end{abstract}

O trecho acima, da diretora norte-americana Anne Bogart, apresenta a importância de saber lidar com as emoções como um aspecto fundamental no treinamento de atores e atrizes. Saber o que concentrar/armazenar e o que deixar que se desfaça é parte dessa autonomia desejável de cada um durante o jogo, e isso ganha ainda mais importância quando se está sozinho, do outro lado da tela. Por isso também é que o enunciado - ou seja, o que explicitamente cada jogo propõe e procura realizar - precisa estar operando todo o tempo, fazendo-se presença contínua, importando mais do que a ausência de quem orienta a ação.

L, de lógica. Uma outra lógica para a criação. Cada atriz ou ator (e também o professor e o diretor) se aproxima de um material e realiza traduções por uma via muito própria, de acordo com o funcionamento do corpo, do intelecto, da história vivida, da cultura em que se está inserido. Esse modo próprio de traduzir é composto de todas as vivências de que somos feitos. Se a criação ocorre agora em outro lugar, será preciso alterar a lógica que conhecemos de nós mesmos, ou ao menos estarmos atentos ao seu funcionamento e complementá-la com alguma coisa extra, que estava adormecida, desconhecida ou inerte. 
Tentativas: (1) Trazer uma cena ou expressão em que se possa dizer, na linguagem escolhida, "quem sou eu hoje?” ou "quem sou eu aqui?”. Essa dinâmica pode ser feita mais de uma vez, sendo "atualizada" no decorrer dos dias de trabalho. (2) Estimular, nos jogos e dinâmicas realizadas, que se ative também a musculatura e a percepção nas superfícies do corpo que não estão de frente para a câmera, com igual importância. (3) Observar com muita atenção e interesse o que o outro realiza em cena, dando espaço a uma devolutiva que priorize o que se viu do que o outro fez, objetivamente, e menos o que se imagina ou se opina sobre o outro fez. (4) Desenvolver dinâmicas de jogo que possam proporcionar outras maneiras de entrar em contato com o outro, como por exemplo escutar mensagens de áudio especialmente enviadas para cada um, já que não se pode ouvir muitas pessoas ao mesmo tempo na tela das plataformas. (5) Dar chance de que todas as coisas e pessoas dos lugares onde cada um está possam ser incluídas no trabalho, sem ignorar o entorno. (6) Criar dinâmicas em que estejam em jogo coisas que possam surpreender: as pessoas da casa, o gato, o cachorro, os ruídos, a água, entre outros materiais. (7) Regular o tempo das dinâmicas de improvisação com dispositivos menos rígidos que o relógio, que exijam uma percepção diferente, como por exemplo a duração de músicas ou mesmo mudanças de luminosidade no ambiente.

Experimentações que ativem memória, imaginação e sentidos, diretamente na ação proposta, são dinâmicas que podem permitir, senão alteração da lógica, ao mesmo ampliação dela e qualidade de presença.

M, de melodrama. Nossas cenas tiveram que se aproximar da linguagem audiovisual, na medida em que migramos para o território virtual, para a mediação das câmeras dos celulares e computadores. A despeito de todas as tentativas de ação crítica, será que nos mantivemos em aspectos do padrão comercial do cinema? Conseguimos politizar nossa ação cênica nas telas ou acabamos por reproduzir clichês que alimentam o mesmo tipo de reação do público que já conhecemos? E quanto à atuação, o quanto de fato fizemos para que ela fosse ao encontro do espectador de maneira não automática, considerando o tipo de relação que queríamos estabelecer? Para além dos temas escolhidos, o quando 
cedemos a uma forma apaziguada, regulada, padrão? Fizemos o mesmo do mesmo, ou abrimos de fato as possibilidades estéticas para criar outros interstícios relacionais? Ao trazer a câmera para mostrar as cenas de nossas próprias casas, avançamos quanto à força estética ou cedemos à já conhecida e simplificada exploração de uma pretensa intimidade entre quem faz e quem olha? Nossas histórias encenadas entenderam, no corpo das cenas, os campos híbridos entre personagem e pessoas, entre casa e linguagem, ou nos deixamos levar pelo viés do melodrama, por um tipo de ação padrão com gestos exagerados e clichês, por narrativas que resultam moralizantes e dentro da bolha temática da família?

Se o melodrama "simplifica as questões em pauta na sociedade, trabalhando a experiência dos injustiçados em termos de uma diatribe moral dirigida aos homens de má vontade" e se "tem sido o reduto por excelência de cenários de vitimização" (Xavier, 2003, p. 93), o que temos sido capazes de fazer? A partir do que apresenta Ismail Xavier, será que o que conseguimos foi somente adaptação à estética das lives num movimento simplificador, submisso e assimilado?

N, de "não ter e ter que ter para dar". O momento atual é, sem dúvida, o maior desafio pedagógico que já vivi. A motivação necessária do professor têm exigido demasiado: para manter a energia de trabalho de criação em alto nível, para mostrar e valorizar o plano a ser desenvolvido e o valor do próprio conteúdo, para estimular e permitir que a sensibilidade e a conectividade continuem presentes e ativas na sala de trabalho, para acolher os alunos, para ser mais compreensiva do que nunca.

Foi preciso ajudar as pessoas na transição para o estudo à distância, mesmo sem saber direito o que fazer, mesmo estando despreparada tecnicamente, mesmo sem ter fé (ao menos no início) nas relações humanas através dos veículos digitais. E foi também preciso, do lado de cá da professora e artista, encontrar novos interesses no assunto que um dia já apaixonou e moveu: estar em cena, valorizar a importância do teatro e da arte pública. E, sobretudo, através da linguagem escolhida para agir no mundo, promover pertencimento, entre alunos, entre alunos e professora, entre alunos e a universidade, entre professores, entre a cena e seus espectadores. 
Mais do que nunca, como alimento afetivo da motivação, eu quis ser a "professora inesquecível", a que será lembrada como "a professora que, em meio à pandemia...”. Há muita coisa em jogo, incluindo o perigo da evasão dos alunos, da desistência. Silva Leite escreveu, a partir de seu grupo temático de pesquisa, que

o mais surpreendente, no entanto, é o fato de os alunos reconhecerem que existe uma profunda relação afetiva entre o professor inesquecível e a sua área de ensino; tal relação é claramente detectada quando os alunos relatam sobre a aula expositiva ministrada pelo professor: é o momento em que ele contagia com a paixão que nutre com os conteúdos abordados, ou seja, os alunos são contagiados por este sentimento percebido na postura e nos conteúdos verbais emitidos pelo professor, que os compartilha com seus jovens parceiros. [...] uma das principais características da emoção: o seu poder de contágio (Leite, 2017, p.168169).

Sabemos que estudar não será sempre prazeroso, a depender das complicações das circunstâncias sociais, familiares e pessoais. Sabemos também que dar aula não será sempre motivo de felicidade. Mas é melhor afastar-se dessa gangorra para compreender que ainda é a mediação pedagógica, entre o estudante e seu objeto de estudo e conhecimento, o principal fator que possibilitará um “movimento de aproximação de natureza afetiva positiva” (Leite, 2017, p.171). São muitos os fatores que podem colaborar ou prejudicar este caminho. Contudo, "Na sala de aula, o professor é, sem dúvida, o principal agente mediador [...] uma vez que todas as práticas pedagógicas são planejadas e desenvolvidas a partir de sua iniciativa" (Leite, 2017, p.173).

Não ter, e ter que ter para dar: apaixonar-se de novo pelo teatro, como nunca antes, acreditar no seu poder de transformação e de cura. E reaproximar de mim a enorme importância de ser educadora.

O, de objetos. Para Shaday Larios, os objetos não estão ilesos às mudanças que nos ocorrem. Na passagem para um contexto de confinamento,

el sentido de la prohibición se revierte y forma una figura de ida y vuelta. Las prohibiciones del uso del espacio público en tiempos de pandemia, provocan a su vez una rebeldía singular hacia la mirada prohibitiva que 
constriñe la movilidad en el espacio privado, y éste se redescubre por vía de pequeños atentados que buscan liberar al cuerpo detenido entre paredes y cosas, acercándolo entonces a otro tipo de conexiones con el entorno doméstico. Ya que el atentado no sólo es hacia el plano de las colocaciones y las funciones, sino también hacia nuestro 'inconsciente material' y nuestro 'inconsciente habitacional (Larios, 2021).

Quase todas as coisas que apareceram em aula, nas cenas e improvisações, tinham grande ligação afetiva com os estudantes. Momentos de isolamento social mudam também as nossas relações com os objetos: o presente recebido de alguém que está distante, a carta escrita no passado sobre desejos de um futuro que se dá agora, a fotografia da avó falecida na parede da sala, o cômodo de bagunça da casa que a mãe não quer que seja visto pela câmera, as plantas que sempre estiveram ali mas que pela primeira vez recebem água suficiente, ou ainda a casa provisória da pandemia que não tem nada que seja pessoal. A materialidade imediata dos objetos serviu como instigadora de afetividade (nem sempre positiva), de memória e gestualidades. Nas dinâmicas de criação, foi possível ver a todo tempo como os alunos dispunham de seus afetos - ou os recusavam deliberadamente - nos cômodos, nos quintais, nas janelas e nas coisas, recuperando ou explicitado relações antes aquietadas.

P, de presença. Insistir na presença. Por fazer parte de grupos de teatro, desde sempre acostumada com a criação em processo colaborativo e com as incertezas das cenas feitas em site specific, meu primeiro impulso foi enfrentar o lugar que agora se mostrava como único possível. Talvez tal lógica tenha permitido, logo de início, problematizar a criação à distância, vê-la como desafio e necessariamente um work in progress entre várias linguagens possíveis:

O caráter multidisciplinar, de cruzamento de diferentes linguagens artísticas, tão axial na performance, é também prática recorrente na encenação atual, que se alia, cada vez mais, às artes plásticas, à dança, à música e ao cinema. [...] Entre outros elementos, ela vai lançar mão da exposição nua e crua do corpo do ator-performer, de sua ampliação imagética - ou de partes dele - por meio de recursos tecnológicos, acentuando o elemento presencial - ou pondo em xeque a sua ausência ou virtualidade (Silva, 2008, p.183).

Embora a perspectiva dessas semelhanças esteja invertida, ou seja, a 
virtualidade tenha se imposto no primeiro plano, assim como a necessidade do uso de recursos tecnológicos, a questão da presença continuou se mostrando crucial. Como seria possível acentuá-la? Qual qualidade de presença seria possível manifestar?

Que modo de ensaiar será preciso para gerar tais ou quais qualidades de relação (entre os atuantes, entre atuantes e os demais presentes, entre os demais presentes); e que modos de ensaiar serão adequados para gerar tais ou quais qualidades de presença (dos atuantes e dos demais presentes? [...] Depende. Depende das necessidades e dos interesses (Fabião, 2013, p.9 - grifos da autora).

Em meio a essa problematização, decidimos insistir nela como forma de acentuação. Tratava-se não de nos apegarmos à presença física da atriz e do ator como condição da linguagem teatral, mas buscar a invenção de algo que pudesse produzir encontro e experiência, ao vivo, entre pelo menos duas pessoas - artista e público. Um processo de criação que insistisse nesta tarefa poderia ser política e pedagogicamente importante.

Q, de queda-de-braço. Nada foi pacífico. Olhando para a experiência, agora, parece até simples, mas não foi. O que primeiro despontou foi uma aversão imediata às aulas remotas, aos espetáculos pela internet; muitos problemas. As conversas eram tensas, ninguém sabia direito a quem enfrentar, nem exatamente o que se mostrava como inimigo e impossibilidade real.

O treinamento de Viewpoints se mostrou poderoso aliado de enfrentamento; afinal, mudar o espaço físico das nossas relações pedagógicas e criativas estava diretamente relacionado a experimentar outros pontos de vista. Questionando sobre os limites do treinamento, a diretora Anne Bogart escreve:

A atitude de uma pessoa frente a qualquer tarefa é determinante para que haja bons resultados. Atitude é fundamental. Como diz o artista plástico Christo, 'não existem problemas, apenas situações'. Chamar algo de problema dá origem a uma relação equivocada com o que está acontecendo, predeterminando uma atitude pessimista e de início derrotista. É muito importante a atitude que trazemos para uma peça, um papel, um ensaio ou um relacionamento.

Podemos treinar atitudes? Podemos treinar a atitude que um ator traz para um ensaio ou para a sua própria carreira? (Bogart, 2009, p.30). 
Não é possível responder a Anne Bogart com conviç̧ão, nem antes e nem agora, com o desafio multiplicado por conta da pandemia. Será que nossas escolhas se restringiam de fato, no início, a escolher entre seguir e paralisar?

Denise Ferreira da Silva e Valentina Desideri, no artigo Leituras (po)éticas, propõem "ferramentas de complexificar os modos pelos quais pensamos, sentimos e atuamos, eticamente e politicamente, no mundo" (Silva e Desideri, 2016, p.69), sem negar que aí também estarão envolvidos aspectos emocionais e espirituais. O texto se tornou importante referência, principalmente porque as autoras apresentam uma fusão entre ética e poética, numa mesma ação.

Ainda que não houvesse desgaste visível em nossa maneira de pensar pedagogia e criação, o momento impôs circunstâncias sem precedentes para a nossa ação estética. As possibilidades apresentadas por Denise e Valentina davam chance de manter as questões em movimento, para além da quebra-de-braço inicial que parecia tomar conta de tudo:

Fazer sentido é movimento, não determinação. Ao contemplar a questão que interrompe o fluxo da existência, ao expor os limites do convencional, do normal, do simples, a tarefa não é apenas identificar o problema e sua solução. Em vez disso, o fazer sentido oferece maneiras de navegar a situação problemática, especulando sobre a possível relação entre elementos de natureza e escala diferentes [...] Pois é ao viver que mudamos a maneira como vivemos, e mudamos a forma como pensamos sobre o viver ao fazê-lo de modo diferente, ao invés de tendo um plano (Silva e Desideri, 2016, p.69).

Neste ponto, as autoras se unem ao pensamento de Kastrup: "a arte é uma das maneiras de trabalhar na direção da problematização e da invenção de si e do mundo. Essa não é a única estratégia, mas fornece efetivamente condições para evitar automatismos perceptivos" (Kastrup, 2016, p.4).

R, da relação com o público, e também das relações de cena entre as atrizes e atores, ou ainda da relação entre as personagens do material dramático escolhido. Ao insistir na ideia de presença ao vivo como foco dos trabalhos, decidimos não compor as peças com materiais previamente gravados. Decidimos também, pelo mesmo motivo, que seria importante "dar uma função ao público", 
ou seja, mantê-lo junto da ação, como coautor, de mãos dadas. Com as necessárias mudanças e adaptações nas dramaturgias originais, o espectador tornou-se uma espécie de contracenador, mantendo-se num limite tênue entre assistir e performar.

Esse limite tornou-se também nosso interesse de estudo, levando-nos a lapidar o jogo dramatúrgico já presente nos textos originais de modo a não deixar escapar uma relação potente de integração, sem, no entanto, cair no equívoco de realizar "simulacros" de interação não realmente disposta. Trazer o público à participação tem sido uma grande tentação dos processos, e muitos trabalhos profissionais têm feito isso. De alguma maneira, a interação parece "resolver" nosso problema com a plataforma virtual, assunto que certamente irá merecer nossa reflexão futura. Portanto, ao fazer uma pergunta para o espectador, no exemplo do nosso trabalho, era preciso ser consequente com a resposta, ouvi-la de fato e considerar, o que acabava levando a dramaturgia por caminhos de abertura, de improvisação, de jogo e performatividade.

Da mesma maneira - outro exemplo que aconteceu durante os processos de criação - dar chances para que o público escolha finais ou desdobramentos diversos mostrou que as linhas narrativas de vídeo games precisariam ser estudadas com interesse. Na grande maioria das trajetórias desses games para adultos, a possibilidade de escolha de caminhos para quem joga está pautada numa forte necessidade interna de continuação e de resolução de problemas. Pensamos, então, que se oferecêssemos escolhas ao público, elas teriam que ser parte da estrutura do trabalho, e não apenas uma curiosidade que não altera nada, nem ninguém.

S, de site specific. Seria possível ver o " lugar nenhum" da internet, espaço último do encontro teatral possível nos dias de hoje, como cheio de possibilidades de relações novas? Seria possível andar nesse lugar como quem descobre geografias? Seria possível, ao caminhar, desprender uma capacidade infantil de olhar, tão infantil quanto possa ser surpreendente, diante do que se vê? Quantas e quais distâncias podem ser assumidas entre as pessoas dos dois lados? É possível ver a internet como um “meio-lugar”, uma "zona mutante”, entre o público 
e o privado, entre o infinito virtual e o linear analógico, entre o agora do lado de cá e o agora do lado de lá, entre uma coisa e outra, entre a possibilidade e a falência, entre o teatro e o cinema, entre o ativo e o passivo, entre a ação e a paixão, entre o morto e o vivo? Pode-se perder em seus labirintos? É possível caminhar por esse território com os pés descalços?

Afinal, o lugar em que temos nos encontrado nos últimos meses é um site. E, como todo lugar, tem suas especificidades e características. Ao invés de declará-lo por aquilo que não é, uma tentativa seria agir e intervir naquilo que se apresenta. O trabalho de arte site specific tem uma natureza que depende e se torna parte inseparável do local em que se faz:

Site specific costuma implicar algo enraizado, atrelado às leis da física. Frequentemente lidando com a gravidade, os trabalhos site specific costumam ser obstinados com a "presença", mesmo que fossem materialmente efêmeros e inflexíveis no que diz respeito à mobilidade, mesmo em face do desaparecimento ou destruição. Seja dentro do cubo branco ou fora no Deserto de Nevada, seja arquitetônica ou orientada para a paisagem, a arte site specific inicialmente tomou o lugar como a localização atual, uma realidade tangível ${ }^{5}$ (Kwon, 2002, p.11).

Em todo trabalho teatral de natureza site specific, o local é elemento decisivo e definitivo na elaboração das dramaturgias e nas características da atuação. A cena feita na internet, se puder ser considerada como trabalho site specific, libera o processo de criação para experimentar diversos registros e dimensões, que podem e devem ser atravessados pela força dos elementos que ali atuam. Portanto, a cena feita ao vivo e virtualmente, ao invés de suavizar e minimizar as condições das plataformas, pode justamente se valer disso para tornar-se parte delas, num “redimensionamento radical em razão dessa ocupação” (Silva, 2008, p. 175) . Vista como site specific, a tela como espaço da cena aumentaria também o caráter político da ação, já que

${ }^{5}$ Site specificity used to imply something grounded, bound to the laws of physics. Often playing with gravity, site-specific works used to be obstinate about "presence", even if they were materially ephemeral, and adamant about immobility, even in the face of disappearance or destruction. Whether inside the white cube or out in the Nevada desert, whether architectural or landscape-oriented, site-specific art initially took the site as an actual location, a tangible reality (Kwon, 2002, p.11). (Tradução nossa.) 
A produção desses espetáculos decorre de uma percepção aguda da politização do espaço urbano, das cidades e do cotidiano, podendo ser mais crítica ou menos crítica em relação às desigualdades reveladas por uma atenção extraordinária aos lugares (Koudela e Almeida, 2015, p.159).

T, de Taira Waraki. Quer dizer pipa, em árabe. Taira Waraki, escrita assim, é a transliteração. Essa palavra e a ideia que a acompanhou nas nossas aulas, como dinâmica pedagógica, foram das mais importantes. Pipa, em árabe: porque há um aluno, na turma em que trabalhamos improvisação teatral, que veio da Síria, como refugiado. E ele nos ensinou essa palavra na sua língua, que imediatamente se tornou palavra-gesto, para nós, de reconhecimento, de abertura e acolhimento.

A pipa e a linha, a pipa no céu e a criança que a empina desde o chão. Taira Waraki, Tairaat Warakieh, no plural. Criamos um procedimento interno nas aulas. Os estudantes se organizam em duplas: as Tairaat Warakieh. Enquanto um das pessoas estiver "voando", a outra será seu lastro no chão. Uma é a pipa, a outra a linha.

O impulso que gerou a criação desse procedimento veio para lidar com uma das maiores dificuldades do teatro sendo feito de maneira remota: a sensação de desamparo, de não pertencimento, de abandono, que acontece quando sabemos que não estamos sendo vistos do outro lado da tela. Uma impressão de "tanto faz", ligar a câmera ou não, estar presente ou não. É bastante comum entre professores a queixa de que nas aulas em geral os alunos não têm ligado suas câmeras. Como espectadora de teatro feito online, muitas vezes me senti de maneira semelhante, sentada na frente do computador, em minha casa. Estar atenta dependia só do meu interesse e da minha capacidade de ver aquilo como coisa importante para mim.

Num contexto pedagógico, essa questão se torna dupla: como lidar com o descaso, tanto na aula quanto na cena, na relação com aquele que vê, com o espectador? A ausência acomodada como comportamento naturalizado precisava ser problematizada, sem que se transformasse em discussões infinitas e de teor moral. Somava-se a isso, também, o fato da turma em questão estar em seu primeiro ano, uma turma em que as pessoas mal se conheciam, nem tiveram chance de estabelecer relações de cooperação e apoio espontâneas. 
Funciona assim, a tentativa: a linha sempre vai estar olhando para sua pipa. Se ninguém mais estiver vendo a cena de um aluno, ele pode ter certeza de que estará sendo visto pela sua linha. As duplas de pipa e linha sabem tudo sobre o que fazem, antes e também depois das aulas, em dinâmicas de estudos e preparo. $\mathrm{Na}$ tela da plataforma de encontro via internet, cada linha seleciona sua pipa e a fixa para vê-la bem. Às vezes a pipa e sua linha entram em cena juntas, e por isso conseguem elaborar melhor os enunciados das tarefas pedidas em sala de aula. A companhia da dupla será também a principal fonte de devolutiva sobre as cenas vistas; embora todos os participantes estejam envolvidos nas conversas após as improvisações, a palavra da pipa é a mais importante, porque dedicou especialmente o seu olhar. A analogia impulsiona a dinâmica mesmo afetivamente: uma criança no chão, de posse da linha e de sua pipa, quer que ela consiga voar, quer admirar a beleza do voo, quer se tornar melhor como lastro e proporcionar mais desenvolvimento da técnica e dos movimentos que a pipa faz no céu.

Para além da sensação de companhia e de audiência garantida, o procedimento permitiu ainda que fossem desenvolvidos, com bom resultado, aspectos relativos à apreciação da linguagem. Assistir às cenas se configurou tão importante quanto fazer, mesmo porque falar sobre o que se viu se tornou momento de protagonismo.

Para uma turma de primeiro ano de graduação, com alunos de outras culturas e diversas experiências, a dinâmica Taira Waraki, entre as pipas e suas linhas, acabou criando um ambiente de confiança, que permitiu e estimulou a abertura de afetos, de pensamentos mais subjetivos e o compartilhamento das visões de mundo. Cada pipa teve em sua criança-linha uma espécie de companhia afetuosa para se aproximar da linguagem. Estar em cena ganhou encontros múltiplos, afetividades diversas, vínculos objetivos de escuta e percepção de si e dos outros.

Por outro lado, como professora, foi importante aceitar que nem tudo estava sob minha atenção e domínio. Houve coisas que não consegui ver, por exemplo, mas que os alunos viram. Fui percebendo, a cada dia, mais câmeras ligadas, maior vontade de falar sobre o trabalho, mais ecos do que acontecia aos estudantes. Também este foi um grande aprendizado, que deu objetividade à ideia de que não 
se pode ensinar a atuar, senão oferecer caminhos:

Quem educa quem? Quem ensina e quem aprende? Como acolher e lidar com as eficiências e deficiências que todos possuem? Como aprender com elas? Como garantir a presença da invenção e da alegria nos processos pedagógicos? Perguntas oportunas para pensar os muitos desafios da educação em tempos de incerteza (Kastrup, 2016, p.5).

Será que podemos inventar zonas múltiplas de vínculo em meio à distância? Será que fizemos isso com as Taira Warak?

$\cup$, de ufanismo. Orgulho exagerado de algo. Orgulho exagerado de estar ativo e fazendo teatro no meio da pandemia, fazendo teatro sem estar no teatro, sem estar na rua, sem estar em companhia física de ninguém. Orgulho de nossa capacidade de inventar, de reagir, de não se deixar abater. Orgulho como estudantes, orgulho como professora, mas...

Permanece lá o avesso da moeda. Se todas as tentativas aqui relatadas foram um gesto um tanto desesperado na direção da continuidade, de se dispor a cartografar canais de efetuação da vida, não houve como apagar a consciência de que estamos inseridos num sistema global que não permite que paremos de produzir, ainda que nossa produção se veja como arte e educação e não necessariamente como objeto de consumo. Convoco o diálogo com o artigo recente de José Fernando Peixoto de Azevedo:

Nos últimos anos, fomos tomados por um vertiginoso excesso de experiências, sob uma cruzada tecnológica que reduz o mundo a um complexo de intensidades. Que, desse excesso, algum déficit existencial tenha sido o saldo, é algo que a experiência do confinamento contraviral talvez confirme, na medida em que parece impor uma outra contabilidade social e afetiva: menos, fazer menos, essa é a percepção a um só tempo crítica e publicitária do momento, sobretudo diante daqueles que se veem impelidos a 'continuar fazendo', 'responder em tempo real', 'não parar', 'seguir de alguma forma' (Azevedo, 2021, p.48).

E se a gente tivesse recusado? E se teatro fosse impossível de se fazer agora? E se resolvêssemos resistir evadindo, não continuando? O que está em jogo para nós, seja na arte ou na Universidade? E se a gente ouvir também Ailton Krenak? 
Talvez estejamos muito condicionados a uma ideia de ser humano e a um tipo de existência. Se a gente desestabilizar esse padrão, talvez a nossa mente sofra uma espécie de ruptura, como se caíssemos num abismo. Quem disse que a gente não pode cair? Quem disse que a gente já não caiu? (Krenak, 2019, p.57).

Não sabemos se as tentativas servem, se serviram. Copo meio cheio ou meio vazio? Quem vai se servir do nosso copo meio cheio? Insistir como maneira de resistir: é via de mão dupla? Qual o antônimo de ufanismo?

V, de vertente dupla. Cada um, aluno e artista. Professora e artista. O empenho do ensino e da pesquisa das artes tem sido fazer com que não haja tanta diferença entre teatro e pedagogia, na medida em que tanto uma coisa como outra produz, ou pode produzir, conhecimento. Ambas as áreas de estudo e pesquisa lidam com aquilo que ainda não se domina, com problematizações, com o que não se sabe, com o que será criado.

Compreender a vertente dupla que movimenta a sala de aula se tornou mais decisiva, no contexto de aulas dadas à distância. Ela tem se apresentado mais explicitamente, como um pêndulo, que ora requisita a autonomia, a autorregulação e a tradução artística efetiva diante do espanto sobre o mundo, e ora pede monitoramento, cuidado, acolhimento, clareza de objetivos e procedimentos no desenvolvimento do processo de criação.

A tentativa para lidar com essa oscilação apareceu intuitivamente, num primeiro momento. Percebi que, quando narrava os contextos nos quais eu mesma havia entendido ou desenvolvido algum ponto do estudo em andamento na sala, as dinâmicas tendiam a fluir melhor, com mais disposição e proficuidade. Ou seja, as narrativas de experiências nas quais a professora estava na condição de aprendiz, ou ainda a diretora estava na função de atriz, multiplicavam as possibilidades sensíveis e intelectuais para abordar os problemas.

Para Narciso Telles (2017, p.189),

Contextualizar o conhecimento possibilita ao aluno: uma maior compreensão de toda a experiência vivida pelo artista-docente, de suas 
tensões e enfrentamentos diante deste elemento técnico, e reconfigura uma relação que não estará baseada na estrutura autoritária de poder [...], que muitas vezes garante ao professor uma incomunicabilidade com seus alunos e o estabelecimento não de uma troca, mas de uma ordem no processo de ensino-aprendizagem.

Compartilhar dos próprios pensamentos e indecisões frente às dificuldades que se apresentavam, enquanto docente, além de explicitar o que está por trás dessas tentativas que disponho neste artigo, por exemplo, fortaleceram o vínculo entre professora e estudantes. Que soubessem que estávamos juntos e ao mesmo tempo descobrindo como se daria o trabalho nas disciplinas, ainda que previamente estruturado pela docente, de certo modo nos tornava não só aliados, mas também cúmplices igualmente implicados no resultados das ações.

X, de xepa. Nas aulas, a xepa da energia, o resto do que a sobrevivência tem demandado. Se o engajamento nas aulas e processos de criação remotos é, em si, uma questão complexa, percebida nas câmeras desligadas e tarefas não realizadas, o baixo tônus aparece como desdobramento que merece atenção especial. Estar em casa, sair da cama e vir direto para a tela - se é que se sai da cama - exige um nível grande de energia que precisa estar à disposição. Quais tentativas, quais dinâmicas poderiam funcionar para aumentar a vontade e o desejo de estar ali, nos encontros?

Numa carta enviada ao lançamento do LabAct - Laboratório de Atuação e Saberes da Prática da UNICAMP, realizado já em meio às condições da pandemia, a artista e pesquisadora Eleonora Fabião escreveu: "que atuemos com extrema posição política, com o devido rigor ético e a energia propositiva necessária para a geração de força estética (abundante e abrangente)" ${ }^{6}$. A partir dessa frase, com o pensamento e o corpo ocupados também com os processos pedagógicos, formulei: como posso fazer do espaço-tempo disposto para os encontros das aulas um território-forja em que a energia que bate seja desejo manifesto, pleno, de vida, sem separabilidade ${ }^{7}$ nem morte?

${ }^{6}$ Em documento próprio da autora, em carta recebida.

${ }^{7}$ O conceito é desenvolvido por Denise Ferreira da Silva no artigo SILVA, Denise Ferreira. Sobre diferença 
Foi a partir dessa questão, da xepa de energia à disposição, que se estruturaram quase todas as tentativas dispostas neste alfabeto-artigo.

Z, de zum. Onomatopeia, mimologismo feito do som do nome da ferramenta digital que permitiu os encontros. Como ferramenta, ofereceu a possibilidade de estar em cena em duplas, em quartetos, em colmeias. Por outro lado, não esgota os temas, não resolve, não é suficiente, porque não garante acesso a todos, nem rapidez, nem escalas maiores para ver melhor. Não deixa a gente falar junto, atrasa palavras e gestos e age como se fosse um controlador que delibera sobre congelamentos das imagens. Entradas e saídas, começo e fim de cenas estão mediados por outras percepções, não mais a depender da ação das atrizes e dos atores. Acontecem pausas imensas e vazias, esperando o quadrado deixar de estar com contorno amarelo, ou o gesto do dedo que vai mudar a cor do ícone do microfone individual, antecipando o desvendamento de quem será o próximo a falar.

"Para olhar no olho de outra pessoa eu tenho que não olhar para o olho dela", disse um dos alunos. Seria preciso que o zum configurasse câmeras mais inteligentes que mirassem no meio dos olhos de quem olhamos e para quem dirigimos nossa atenção. Seria preciso resgatar a capacidade de olhar nos olhos, uns dos outros, ao mesmo tempo, como na vida.

\section{Referências}

AGAMBEN, Giorgio. O que é um dispositivo? Outra travessia, Florianópolis, n.05, p. 13-14, 2005. Disponível em:

https://periodicos.ufsc.br/index.php/Outra/article/view/12576. Acesso em: 13 jun. 2021.

AZEVEDO, José Fernando Peixoto. "Entre o gatilho e a tempestade": racismo, capitalismo, teatro e a capacidade mimética de um vírus. Disponível em: https://www.n-1edicoes.org/textos/3. Acesso em: 12 de junho de 2021. 
BOGART, Anne. Seis coisas sobre o treinamento de atores. Urdimento - Revista de Estudos em Artes Cênicas, Florianópolis, v. 1, n.12, p.29-40, 2009.

BORUCHOVITCH, Evely.; BZUNECK, José Aloyseo. (Orgs.). A motivação do aluno: contribuições da psicologia contemporânea. Petrópolis: Vozes, 2009.

CHAUÍ, Marilena. Marilena Chauí. In: CORDEIRO, Denilson e FURTADO, Joaci (orgs.). Arte da aula. São Paulo: Edições SESC, 2019.

COUTINHO, Eduardo. OHATA, Milton (org.). Eduardo Coutinho. São Paulo: Cosac Naify/SESC, 2013.

FABIÃO, Eleonora. Corpo cênico, estado cênico. Revista Contrapontos - Eletrônica, vol. 10, n.03, p. 321-326, set-dez 2010. Disponível em: https://siaiap32.univali.br/seer/index.php/rc/article/view/2256/1721. Acesso em: 13 jun. 2021.

FABIÃO, Eleonora.. Programa Performativo: o corpo-em-experiência. Revista do Lume: Núcleo Interdisciplinar de Pesquisas Teatrais - UNICAMP, Campinas, 2013. Disponível https://www.cocen.unicamp.br/revistadigital/index.php/lume/article/view/276. Acesso em: 13 jun. 2021.

KASTRUP, Virginia. Educação e Invenção em Tempos de Incerteza. Caderno pedagógico 32a. . Bienal de São Paulo. 2016.

KOUDELA, Ingrid e ALMEIDA JUNIOR, José Simões. Léxico de Pedagogia do Teatro. São Paulo: Editora Perspectiva/SP Escola de Teatro, 2015.

KRENAK, Ailton. Ideias para adiar o fim do mundo. São Paulo: Companhia das Letras, 2019.

KWON, Miwon. One place after another - site specific art and locational identity. Cambridge, Massachusetts: The Mit Press, 2002.

LARIOS, Shaday. Casa y teatro de objetos. In: Titeresante, 20 de abril de 2020. Disponível em: http://www.titeresante.es/2020/04/casa-y-teatro-de-objetosintimidad-del-espacio-domestico-en-tiempos-de-guardar-distancia-por-shadaylarios/. Acesso em: 20 abril 2021.

LEITE, Sergio Antonio da Silva. A afetividade como objeto de pesquisa. In: BORUCHOVITCH, Evely, AZZI, Roberta Gurgel, SOLIGO, Ângela (Orgs.). Temas em psicologia educacional. Campinas: Mercado das Letras, 2017, p. 151-181.

OITICICA, Helio. Aspiro ao grande labirinto. Rio de Janeiro: Editora Rocco, 1986.

ROLNIK, Suely. Cartografia sentimental. Porto Alegre: Sulina; Editora da UFRGS, 2014. 
SARRAZAC, Jean-Pierre (org.). Léxico do drama moderno e contemporâneo. São Paulo: Cosac Naify, 2012.

SILVA, Antonio Carlos de Araújo. A encenação no coletivo: desterritorializações da função do diretor no processo colaborativo. 2008. Tese (Doutorado em Artes) Escola de Comunicações e Artes - Universidade de São Paulo.

SILVA, Denise Ferreira. Sobre diferença sem separabilidade. Catálogo da 32a. Bienal de Arte de São Paulo, 2016. Disponível em:

<https://issuu.com/amilcarpacker/docs/denise ferreira da silva ?fbclid=IWAR1AJ G8KxH-69xQOKtfOnRrv3bJfzomlPO-NuwvlJZTUukjDaGZLZ-3vEN8> Acesso em: 02 jun. 2021.

SILVA, Denise Ferreira e DESIDERI, Valentina. Leituras (Po)éticas. Cadernos de Subjetividade, n.19, p.61-70, 2016. P. 69. Disponível em: https://revistas.pucsp.br/index.php/cadernossubjetividade/article/view/38145.

Acesso em: 13 jun. 2021.

TELLES, Narciso. Demonstração técnica/demonstração de trabalho: narrativas da experiência. In: Artes da cena - Estudos sobre Atuação e Encenação, p.187-198. Jundiaí, SP: Paco Editorial, 2017.

XAVIER, Ismail. O olhar e a cena. São Paulo. São Paulo: Cosac Naify, 2003.

Recebido em: 15/06/2021

Aprovado em: 30/09/2021 